\title{
A New Approach for Split Renal Function Assessment Based on 3D-Models Generated from Contrast-enhanced Multi-slice Computed Tomography (Msct) Scans and Mathematical Analysis: A Pilot Study
}

\section{P V Glybochko1, Yu G Alyaev¹, S B Khokhlachev², N K Dzeranov ${ }^{1}$, V V Borisov'1,

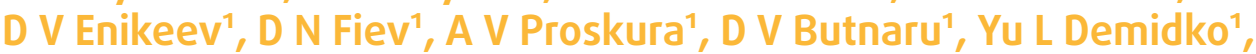 and $M$ V lurova}

${ }^{1}$ Research Institute of Uronephrology and Human Reproductive Health, I.M. Sechenov First Moscow State Medical University, Ministry of Health of Russia; 8 bld. 2 Trubetskaya st., Moscow, 119991, Russia

${ }^{2}$ Central Scientific and Research Institute for Dentistry, Moscow, Russia

Corresponding Author:

M V lurova

yurova.maria.vladimirovna@ gmail.com

Received: 10 February 2018

Accepted: 14 April 2018

Published: 7 May 2018

Publishing services provided by Knowledge

(c) P V Glybochko et al. This article is distributed under the terms of the Creative Commons

Attribution License, which permits unrestricted use and redistribution provided that the original author and source are credited.

Selection and Peer-review under the responsibility of the RFYS Conference Committee.

\section{G OPEN ACCESS}

\section{Abstract}

Introduction: Instrumental methods of examination may alter the course of treatment and patients' management: from minimally invasive nephron-sparing procedures to radical operations. Objective:to present preliminary data on split kidney function assessment (in a kidney volume, e.g. segment) in patients with urological diseases. Materials and methods: A prospective study was launched in aResearch Institute for Uronephrology and Reproductive Health from November, 2015 to February, 2017. 31 patients were enrolled into the study: 15 with stone kidney disease, 2 with kidney anomalies, 14 with renal tumors. Contrast-enhanced CT with 3D-models and mathematical analysis were performed in all patients. Correlation between CT-based and renal scintigraphy-based measures of split renal function was estimated. Results: CT-based methods for the calculation of split renal function with 3D-models showed correlation with renal scintigraphy ( $p<0.004$, ttest). Conclusion: A new approach for split kidney function assessment based on contrast-enhanced CT with 3D-models and mathematical analysis allows for both acquiring detailed data on clinical anatomy and evaluation of renal function to promote preoperative decision-making.

\section{Introduction}

With respect to providing comprehensive and accurate information about tumor size and shape in relation to the kidney and adjacent organs and tissues, contrast-enhanced multi-slice computed tomography has become a commonly used imaging modality in urology. Modern MSCT scanners allow for performing a three-dimensional (3D) 
rendering of a region of interest (ROI) and thus leading to well-balanced decisionmaking in advanced renal tumor. The evaluation of split renal function is traditionally based on renal scintigraphy data (RS). RS with technetium-99m MAG3 is utilized to measure kidney function. Injection of a radioactive tracer is followed at 2 minutes by measurement of the amount of decay from each kidney. It is a researcher-dependent way of split kidney function assessment. As well as that results of RS may depend on patient's weight and patient's body movements during the procedure $[2,7]$. However, it is commonly used in the clinical settings $[4,5,8]$.

Contrast-enhanced MSCT is a 4-phase investigation providing a series of images in non-enhanced, arterial, venous, and excretory modes. Modern MSCT scanners allow for performing a 3D-reconstruction of a ROI in every phase. Presumably, fusion of all the phases into a $3 \mathrm{D}$-image would facilitate better understanding and interpretation of the preoperative imaging data and lead to a carefully-weighted decision-making in advanced renal tumor [9]. Images are reconstructed with a $1 \mathrm{~mm}$-slice thickness in multiple planes. An Amira Version 5.4. (Konrad-Zuse-Zentrum, Berlin) software was used to generate $3 \mathrm{D}$ CT-models [6]. As it was demonstrated in the previous papers utilizing Amira software may aid for decision-making leading to less operative time, blood loss, warm ischemia time, length of hospital stay and negative surgical margins [3]. Currently, Amira is routinely used in aResearch Institute for Uronephrology and Reproductive Health for preoperative decision-making. However, we aim to present data on Amira for split renal function assessment.

\section{Objective}

To present preliminary data on split renal function assessment based on 3D-models generated from contrast-enhanced multi-slice computed tomography (MSCT) scans and mathematical analysis and assess correlation between CT-based and RS split renal function data.

\section{Materials and Methods}

From November, 2015 to February, 201731 patients were enrolled into a prospective study launched in a Research Institute for Uronephrology and Reproductive Health. Inclusion criteria were as follows: 1) patients wirh urological diseases leading to kidney function loss; 2) availability of contrast-enhanced MSCT and renal scintigraphy clinical data. Exclusion criteria: voluntary abandonment from further work-up or no available 
clinical data at a 3 months follow-up. The mean age of patients was 58 years $(\mathrm{Cl} \pm$ 21.7). 3200-4200 Hounsefield unit (HU) radiopaque agents were used to perform MSCT. Algebraic determination of split renal function was performed with Amira Version 5.4. software (licence number ASTND.44644). An IT-specialist was blinded to the results of RS.

MSCT data was copmared to RS and histopathological findings Statistical analysis of data obtained was performed using MedCalc Statistical Software version 17.0.4 (MedCalc Software bvba, Ostend, Belgium; 2017).

\section{Results}

\subsection{Mathematical analysis of $3 \mathrm{D}$-models generated from contrast-enhanced multi-slice computed tomography (MSCT) scans}

4-phase abdominal CT-images included non-enhanced, arterial, venous, and excretory phase data sets. The following protocol was established: 1 ) pre-contrast scans $\left(t_{1}\right)$; 2) arterial scans (shortly after a contrast reaches the renal arteries); 3) parenchymal scans (50 to 60 seconds after the arterial phase); 4) excretory scans (7 minutes after the arterial phase). Images were collected in a DICOM-format. Original images are mispresented for further analysis due to "white noise" distortion (noise containing many frequencies with equal intensities) (Figure 1). Application of various filters allow for better image quality acquisition. (Figure 2).

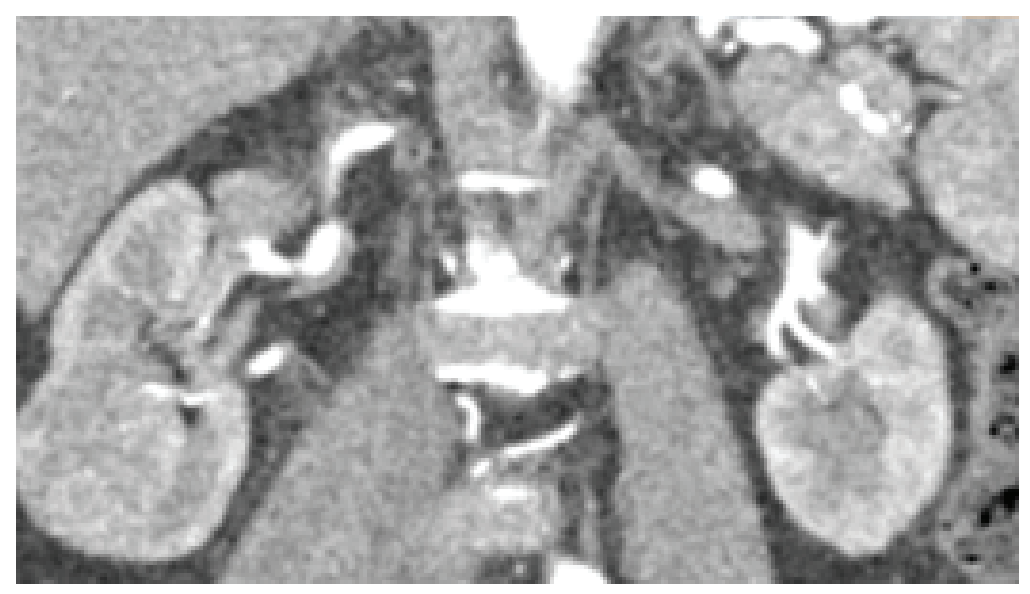

Figure 1: Frontal scan. Original image distorted with white noise.

Amira 5.4.5 software tools allow freeing the margins of the kidney from adjacent organs with similar attenuation. Structures with different attenuation values can be "added" to or "subtracted" from the model. Figure 3 shows kidney cyst (upper pole) 


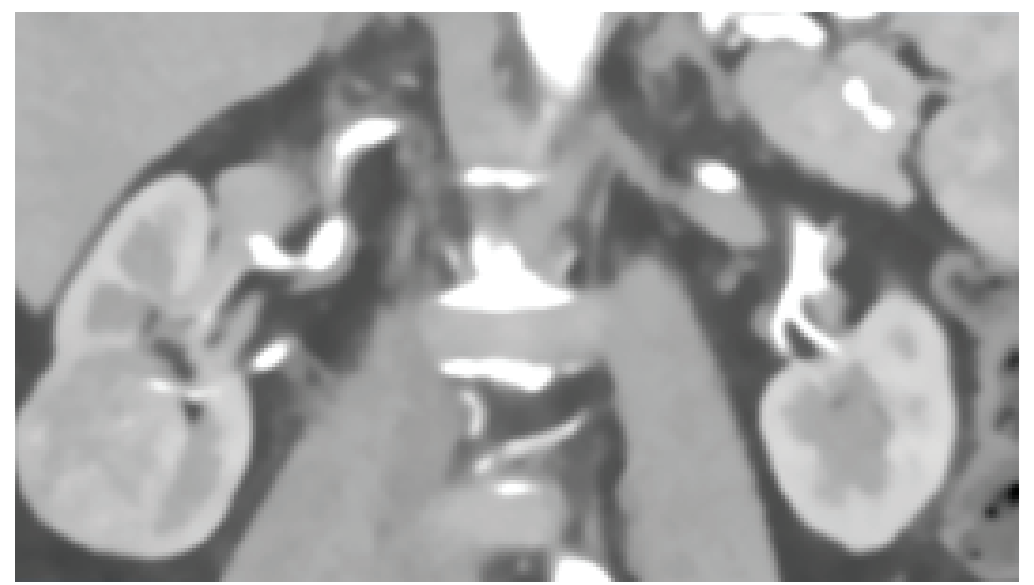

Figure 2: Non-local Means filter is applied: long wavelength noise is reduced.

and a kidney lesion (lower pole). Cysts do not accumulate contrast agent so they do not affect mathematical analysis. However, kidney lesions being highly vascularized (Figure 4) need to be subtracted from the 3D model (1) by estimating radiological density of a contrast agent $n\left(x, t_{i}\right)$ at a $t_{i}$ time:

$$
n\left(x, t_{i}\right)=-1000 * 1 \text { (inside the lesion) }+n\left(x, t_{i}\right) * 1 \text { (outside the lesion), }
$$

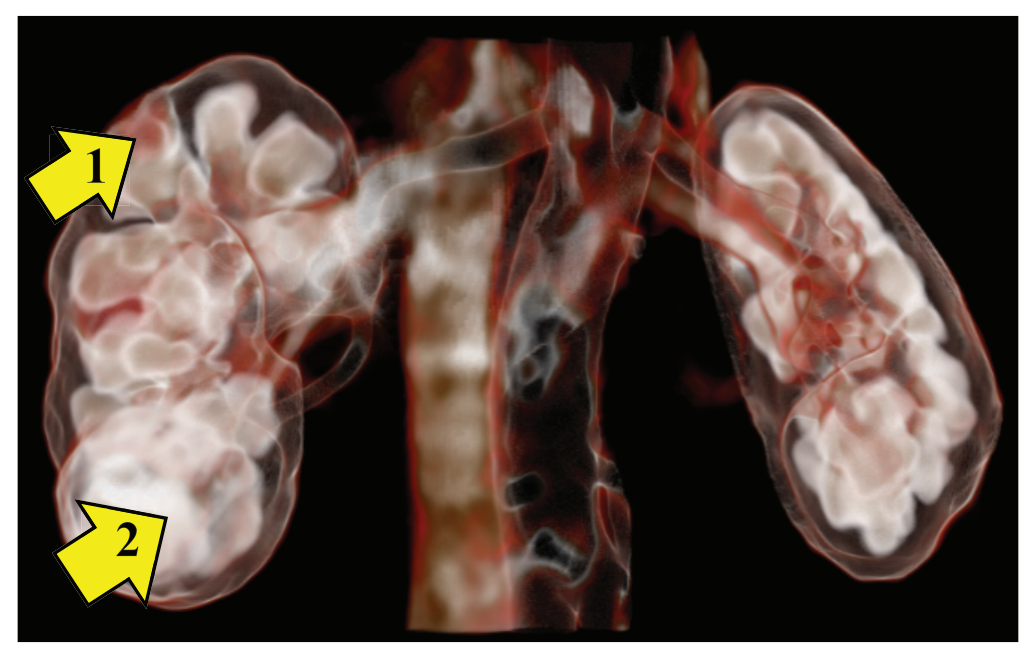

Figure 3: 3D model: regions of interest with high attenuation are made transparent. Arrows: 1 - kidney cyst (upper pole), 2 - kidney lesion (lower pole).

Regions of interest with high attenuation and regions with plenty of contrast agent (veins and arteries) are "substracted" (Figure 5). Crust relative contrast flows are compared in the left and right kidney (2).

$$
\operatorname{CrustStream}(R)=\frac{100 * M_{\text {crust }(R)}}{M_{\text {crust }(R)}+M_{\text {crust }(L)}}, \quad \text { CrustStream }(L)=\frac{100 * M_{\text {crust }(L)}}{M_{\text {crust }(R)}+M_{\text {crust }(L)}},
$$

where CrustStream- percent of the contrast agent into the cortex; $M$ - «mass» of contrast agent in a selected volume of right $(R)$ or left $(L)$ kidney. 


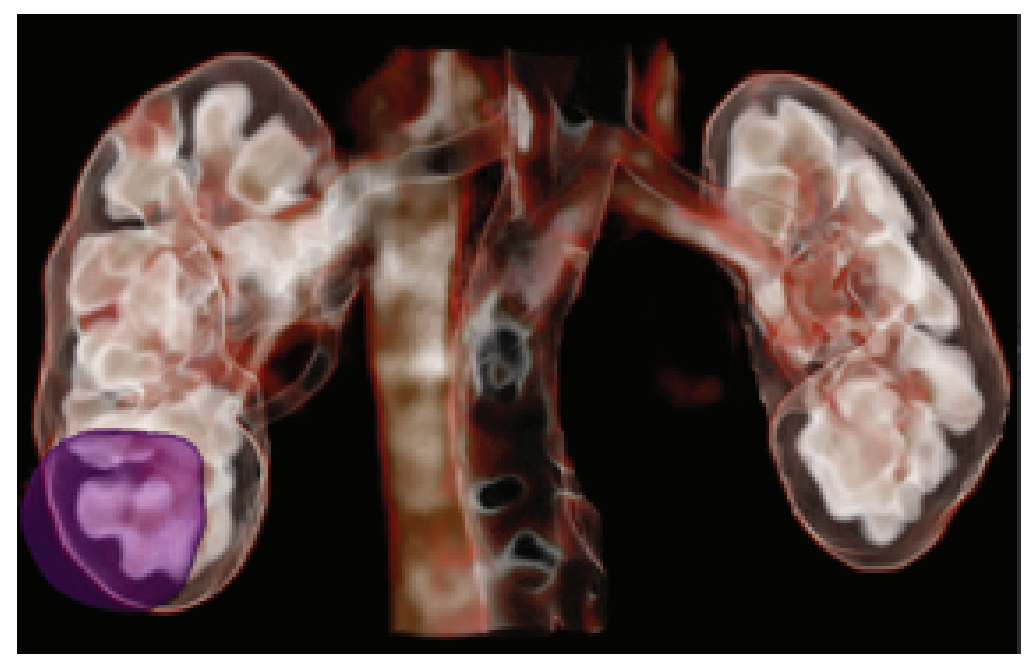

Figure 4: Lesion is outlined and "substracted" from the 3D model.

50-60 seconds $\left(t_{2}\right)$ after the arterial phase another scan is performed (Figure 6). Contrast agent delivered to the cones ( $\left.\Delta M_{\text {urine 1(2) }}\right)$ of the kidney is assessed (3):

$$
\Delta M_{\text {urine 1(2) }}=\sum_{x \text { in (cones) }} \Delta n_{\text {urine } 1}\left(x, t_{2}\right) * \Delta V .
$$

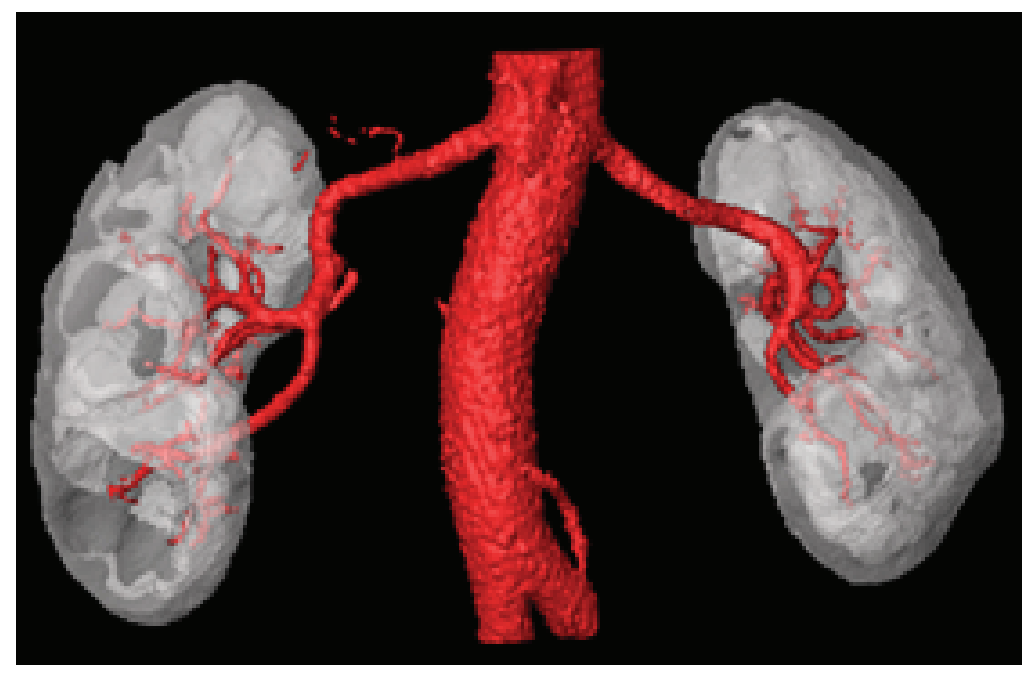

Figure 5: Crust regions of interest are outlined.

7 minutes after the arterial phase another scan is performed $\left(t_{3}\right)$ - excretory phase. Secondary urine formation can be estimated in this phase. However, due to the fact that urine from each kidney is mixed in the bladder total contrast agent release can be assessed (Figure 7).

Label Voxel mode is used to outline region of contrast agent distribution (Figure 8). An important characteristic of kidney function is an ability of the renal cortex (nephrons) to produce urine. This value $\left(U_{t o t}\right)$ can be calculated (4) by dividing the 


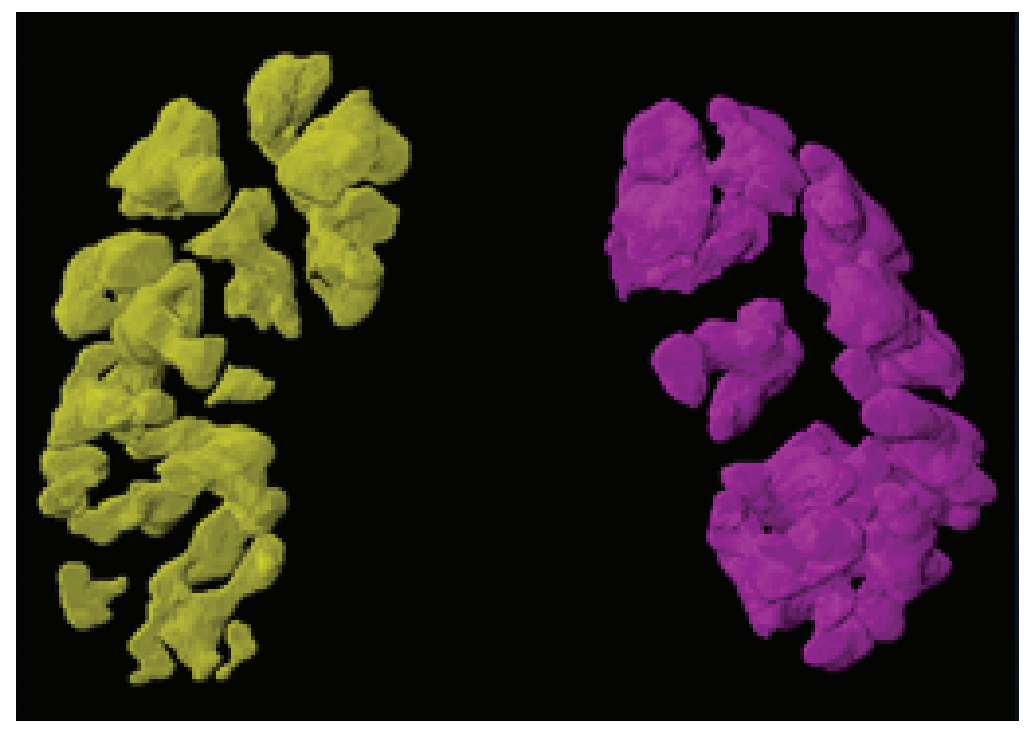

Figure 6: Cones of the kidney filled with primary urine.

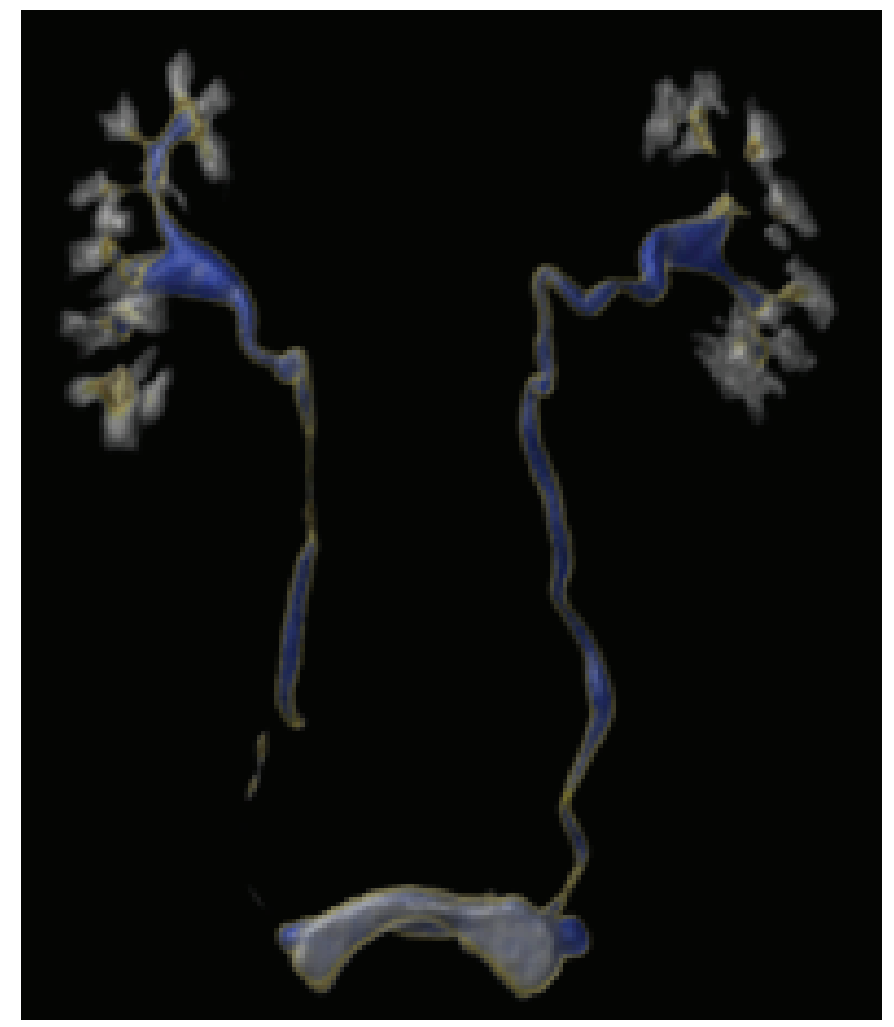

Figure 7: Total contrast agent distribution in the upper urinary tract and bladder.

volume of radiopaque agent excreted by the $7^{\text {th }}$ minutes by the volume $\left(V_{\text {crust }}\right)$ of the cortical layer of the parenchyma $(P)$ :

$$
U_{\text {tot }(R \text { or } L)}=\operatorname{tot} * P_{(R \text { or } L)} / V_{\text {crust }(R \text { or } L)} \text {. }
$$

Tot (\%) characterizes the excretory function of the kidneys. If a patient has stones in the pyelocaliceal system, then their "mass" in HU must be subtracted from the mass that 


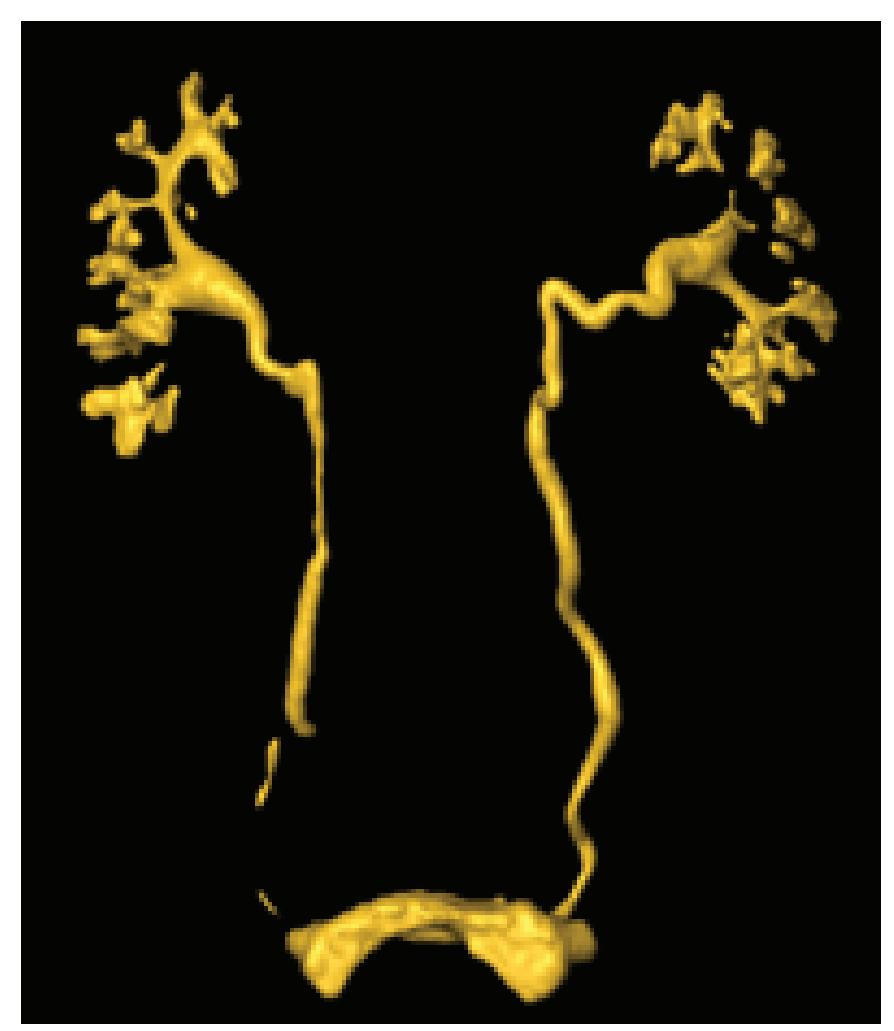

Figure 8: Contrast agent distribution in the upper urinary tract and bladder.

we obtained earlier, adding $n\left(x, t_{3}\right)$ over the selected area in order to obtain the "mass" of contrast agent brought with secondary urine. Separately calculating the masses of contrast agent, we find the distribution of contrast agent in the secondary urine of the left and on the right (5):

$$
P_{R}=\frac{M_{R}}{M_{L}+M_{R}}, \quad P_{L}=\frac{M_{L}}{M_{L}+M_{R}} .
$$

However, it is quite rare that the contrast agent filtered by both kidneys reaches the bladder at a different time and rate (e.g.: unilateral obstruction of the upper urinary tract). From the entire flow of contrast agent, part of it enters the urinary tract and another one goes back to the veins. Coefficient $K_{2,3}$ helps to assess the distribution of contrast agent flows to the kidney and to the veins (6). This coefficient can be estimated by dividing the amount of contrast agent in the entire parenchyma in the venous phase (the moment when contrast agent passed the renal arteries and reached the nephrons) by the amount of the contrast agent of this kidney in the excretory phase:

$$
K_{2,3}=M_{\text {parenchyma }(2)} / M_{\text {urine_2(3) }} \text {. }
$$


By the value of $K_{2,3}$, one can judge the division of the total flow of contrast agent between blood supply systems and urine formation. For the reference value, we calculated the coefficient $K_{2,3}$ in a healthy 21-year-old volunteer with $100 \mathrm{ml}$ of contrast agent at a rate of $4 \mathrm{ml} / \mathrm{sec} \approx 0.7$.

In general, the described approach makes it possible to judge the segmentary function of the kidneys.

\subsection{Renal scintigraphy (RS)}

In addition to the technique based on the assessment MSCT kidney data with contrast, in this researchwork we compared the renal function obtained by RS. The results were analyzed, - a statistically significant correlation between two methods of split renal function assessment was observed (Figure 9, 11).

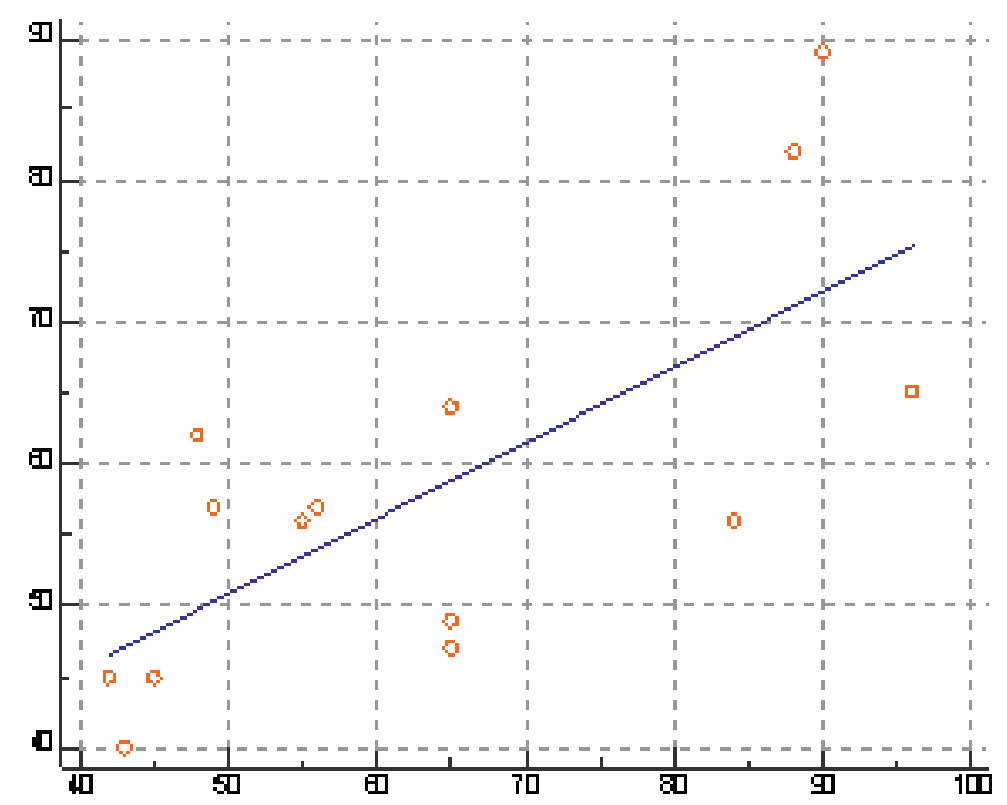

Figure 9: Comparison of data on perfusion of the right kidney obtained with RS and MSCT $(y=24,2952+$ $0,5318 x ; P=0,0038)$.

\subsection{Histopathological data}

When studying the structures of the renal parenchyma via microscopy, changes were revealed. In patients with hydronephrosis, pathomorphological data indicated a significantly reduced functional ability of the kidney tissue (Figure 11), which is more correlated with the results of the mathematical analysis of MSCT kidney data with contrast than with data from RS (Figure 12). 


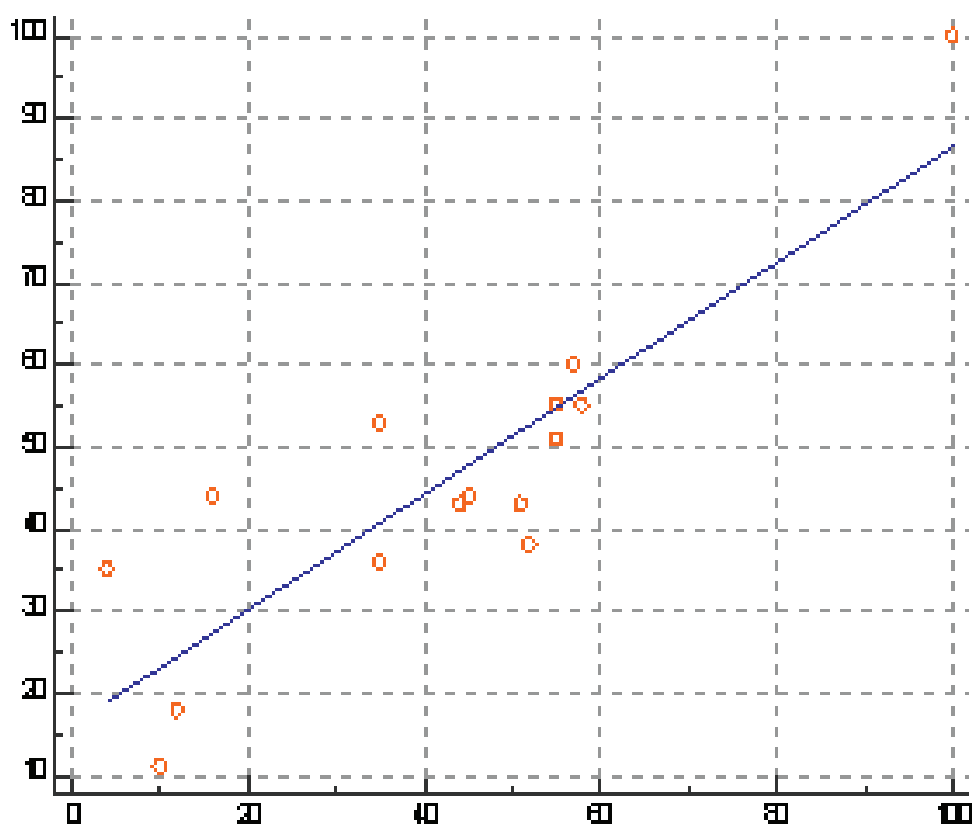

Figure 10: Comparison of data on perfusion of the left kidney obtained with RS and MSCT $(y=16,2004+$ $0,7043 \mathrm{x} ; \mathrm{P}<0,0001)$

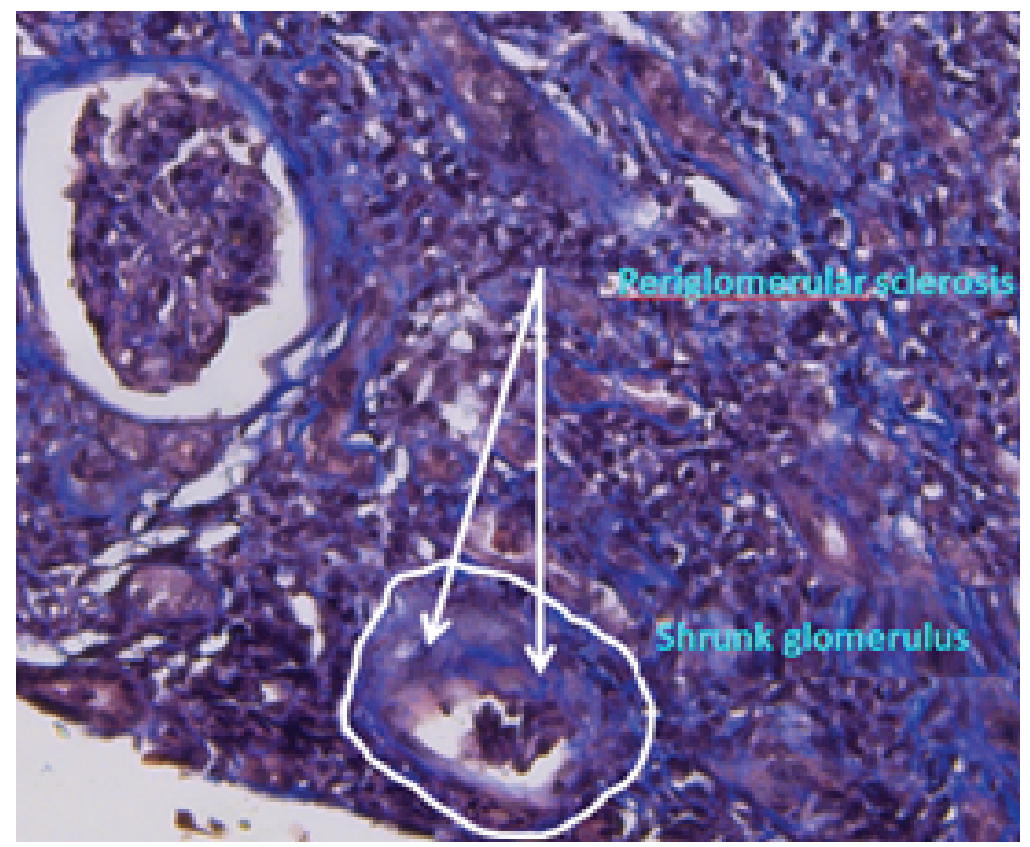

Figure 11: Light microscopy (x 200). Kidney glomeruli (arrows show shrunk glomerulus). Masson's trichrome stain.

\section{Conclusion}

We aimed to present preliminary data on split kidney function assessment by means of contrast-enhanced CT with 3D-models and mathematical analysis and show correlation 


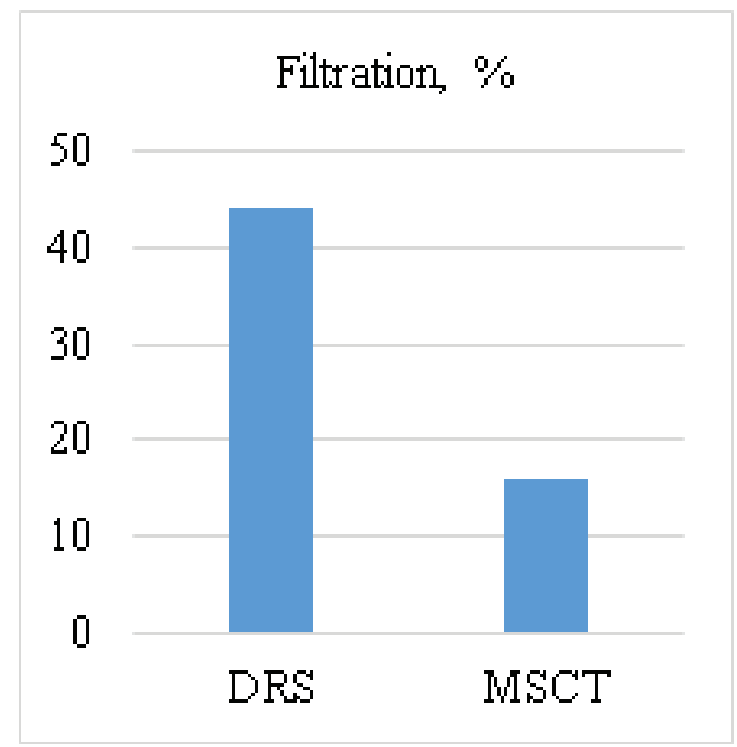

Figure 12: Data RS and MSCT with numerical processing of data on the functional ability of the kidney.

between this method and renal scintigraphy in terms of split renal function assessment. Seemingly, contrast-enhanced CT with 3D-models and mathematical analysis made it possible to obtain results on split renal function that are not inferior to RS. However, according to the data obtained, the new method considered has an advantage over RS in assessing the state of the kidney parenchyma in conditions of retentional compression caused by hydronephrosis. Thus, the method of mathematical analysis of $3 \mathrm{D}$ images obtained with the help of MSCT is an improved method for preoperative decision-making with the help of the Amira software. This method allows not only to evaluate the topographic relationships of structures in the area of surgical interest, but also to more accurately select the amount of intervention, based on the preservation of organ function in the preoperative and postoperative periods.

\section{Ethics statement}

The study was duly approved by the Institutional Ethics Committee. All patients included in the study had given their informed consent.

The authors have no conflicts of interest to disclose.

\section{Acknowledgements}

We are thankful to the patients for allowing us to publish the data collected during their treatment. 


\section{References}

[1] El-Diastya M T, Gaballab G, Gadc H M, Borgb M A, Abou-Elgharc M E, Sheirc K Z and El- Diastyc T A 2016 Evaluation of CT perfusion parameters for assessment of split renal function in healthy donors The Egyptian Journal of Radiology and Nuclear Medicine 47-4 1681-88

[2] Lin K-J, Huang J-Y and Chen Y-S 2011 Fully Automatic Region of Interest Selection in Glomerular Filtration Rate Estimation from 99mTc-DTPA Renogram Journal of Digital Imaging24(6) 1010-23

[3] Fiev D N 2015 Virtual modelling for preoperative decision-making in kidney deseases(Moscow) pp 3-42

[4] Wesolowski C A, Wanasundara S N, Wesolowski M J, Erbas B and Babyn P S Eur2016 J Nucl Med Mol Imaging 43: 550.

[5] Nilsson H., Wadström J., Andersson L.-G., Raland H. and Magnusson A. Measuring split renal function in renal donors: can computed tomography replace renography? Acto Radiologica 45-4, pp. $474-480$

[6] Alyaev Yu G et al 201430 technology for kidney surgery: from virtual to real surgeryedP V Glybochko and Yu G Alyaev(Moscow: GEOTAR)pP 5-280

[7] Veenboer, P. W., Hobbelink, M. G. G., Ruud Bosch, J. L. H., Dik, P., van Asbeck, F. W. A., Beek, F. J. A. and de Kort 2015 Diagnostic accuracy of Tc-99m DMSA scintigraphy and renal ultrasonography for detecting renal scarring and relative function in patients with spinal dysraphism. Neurourol. Urodynam.,34: 513-518.

[8] Kumar K, Ahmad A, Kumar S, Choudhry V, Kumar R, Singh T M and Muzaffar M A 2015 Evaluation of renal histopathological changes, as a predictor of recoverability of renal function following pyeloplasty for ureteropelvic junction obstruction Nephro Urol Mon. 7(4): e28051.

[9] Torimoto I, Takebayashi S, Sekikawa Z, Teranishi J, Uchida K and Inove T 2015 Renal perfusional cortex volume for arterial input function measured by semiautomatic segmentation technique using MDCT angiographic data with $0.5-\mathrm{mm}$ collimation AJR Am J Roentgenol. 204(1):98-104. 